\title{
Segmentasi Gigi pada Dental Panoramic Radiograph untuk Identifikasi Manusia
}

\author{
Latifah Ramadhana Murilmiani Effendhi ${ }^{1}$, Ade Jamal ${ }^{1}$, Solechoel Arifin ${ }^{1}$, Teguh Widodo ${ }^{2}$ \\ ${ }^{1}$ Program Studi Teknik Informatika, Fakultas Sains dan Teknologi, Universitas Al Azhar Indonesia, Komplek \\ Masjid Agung Al Azhar, Jalan Sisingamangaraja, Kebayoran Baru, Jakarta Selatan 12110 \\ ${ }^{2}$ Poliklinik Gigi dan Mulut, Rumah Sakit Pusat Angkatan Darat - Gatot Soebroto, Jalan Abdul Rahman Saleh \\ Raya No. 24, RT.6/RW.1, Senen, Jakarta Pusat 10410
}

Penulis untuk Korespondensi/E-mail: $\underline{\text { latifahrme@gmail.com }}$

\begin{abstract}
Abstrak - Indonesia memiliki tingkat kerawanan tinggi terhadap bencana alam dan kecelakaan yang mengakibatkan terjadinya korban massal. Banyak cara untuk mengidentifikasi korban, salah satunya menggunakan citra gigi. Gigi merupakan bagian dari tubuh yang lebih tahan lama karena struktur gigi yang padat dan kuat. Identifikasi menggunakan sarana gigi dapat dilakukan dengan cara membandingkan data gigi yang telah diperoleh dari pemeriksaan gigi jenazah yang tidak dikenal (data postmortem) dengan data gigi yang sebelumnya pernah dibuat (data antemortem). Terdapat beberapa tahapan dalam melakukan identifikasi korban menggunakan citra gigi. Tahapan yang dilakukan oleh peneliti adalah tahap segmentasi gigi. Pertama, citra dilakukan cropping hingga mendapatkan dimensi berukuran $1564 \times 589$ piksel serta perbaikan citra menggunakan Histogram Equalization. Selanjutnya dilakukan pemisahan citra gigi menggunakan metode Integral Projection dilengkapi penggunaan Spline Interpolation untuk menggambar garis pemisah antara rahang atas-bawah serta gigi tunggal. Tiap citra memiliki nilai n-blok kolom yang berbeda sehingga dibutuhkan parameter sebesar 3 hingga 30 n-blok kolom untuk membentuk garis pemisah rahang atas-bawah. Citra gigi berjenis Dental Panoramic Radiograph. Hasil evaluasi kesalahan terkecil saat melakukan pemisahan rahang atas-bawah menggunakan Horizontal Integral Projection sebesar 56.8\% dengan nilai n-blok kolom adalah 8 dan saat segmentasi gigi pada tahap Vertical Integral Projection sebesar 38.27\% dengan nilai average filter adalah 17.
\end{abstract}

Abstract - Indonesia has a high level of vulnerability to natural disasters and accidents that result in mass casualties. There are many ways to identify victims, especially by using dental images. The teeth are part of the body that are more durable because of the solid and strong tooth structure. Identification using dental images can be done by comparing dental data that has been obtained from unknown victim dental examination (postmortem data) with dental data previously made (antemortem data). There are several stages in identifying victims using dental images and researcher worked on tooth segmentation stage. First, the image need to cropped up to get dimensions size of $1564 \times 589$ pixels and improved contrast using Histogram Equalization method. Then, tooth separation is performed using Integral Projection method which is equipped with the use of Spline Interpolation to draw the separator line between the upper-lower jaws and single tooth. Each image has a different n-block column value, so researcher selected range number of n-block column is between 3-30. In this reseach, dental panoramic radiographs are used. The smallest error rate in the images is found when performing an Integral Projection to separate upper and lower jaws by $56.8 \%$ with n-block column value $=8$ and when separating each tooth from the image by $38.27 \%$ with average filter value $=17$.

Keywords - Antemortem, Postmortem, Segmentation, Histogram Equalization, Integral Projection, Spline Interpolation

\section{PENDAHULUAN}

$\mathrm{B}$ encana dapat diakibatkan baik oleh alam maupun manusia. Berbagai kejadian yang memakan banyak korban jiwa, sejak kejadian Bom Bali I yang menjadi pemicu dilakukannya identifikasi korban bencana massal (Disaster Victim Identification) menjadi kegiatan yang penting untuk dilakukan ketika terjadi bencana yang menimbulkan korban jiwa dalam jumlah yang banyak. Setiap bencana massal yang menimbulkan banyak korban jiwa, baik akibat bencana alam maupun bencana 
yang dibuat oleh tangan manusia, memiliki spesifikasi tertentu yang dapat membedakan antara kasus satu dengan lainnya.

Dokter gigi memiliki peran penting dalam pembuatan data berupa odontogram yang dapat digunakan untuk identifikasi. Maka dari itu, identifikasi manusia yang merupakan data pribadi sangat diperlukan, terutama gigi geligi yang melekat erat pada tulang rahang, tahan terhadap proses pembusukan, tahan terhadap panas sampai 900 derajat Celsius, tahan terhadap asam, dan tahan terhadap abrasi maupun atrisi. [1]

Menurut drg. Wieke Lutviandari DFM (Divisi Odontologi Forensik Instalasi Kedokteran Forensik/Medikiolegal RSUD dr Soetomo Surabaya), pemanfaatan ilmu kedokteran gigi untuk membantu proses identifikasi korban bencana massal di Indonesia telah dilakukan sejak kecelakaan tenggelamnya kapal penumpang Tampomas II di perairan Masalembo, Sulawesi pada tahun 1981. Umumnya, korban yang membutuhkan keahlian dokter gigi forensik adalah korban yang hangus terbakar dan mengalami pembusukan tingkat lanjut yang sulit untuk dikenali dan tidak dapat dilakukan indentifikasi melalui pemeriksaan konvensional lainnya. [2]

Identifikasi menggunakan sarana gigi menjadi sangat penting karena Indonesia memiliki tingkat kerawanan tinggi terhadap bencana, terutama bencana gunung meletus, tsunami, gempa, dan bencana alam lainnya. Juga kecelakaan yang mengakibatkan korban massal yang tidak terduga dapat terjadi, seperti kecelakaan pesawat. Kejadian yang baru saja terjadi di Indonesia seperti gempa bumi dan tsunami yang terjadi di Sulawesi Tengah (28 September 2018) [3] dan kecelakaan pesawat Lion Air JT610 (29 Oktober 2018) [4] itulah yang semakin menguatkan untuk dibutuhkannya identifikasi korban menggunakan citra gigi.

Identifikasi menggunakan sarana gigi dapat dilakukan dengan cara membandingkan data gigi yang telah diperoleh dari pemeriksaan gigi jenazah yang tidak dikenal pada saat kejadian (data postmortem) dengan data gigi yang sebelumnya pernah dibuat (data antemortem). Cara pengidentifikasian yaitu dengan membandingkan data antemortem dengan postmortem yang hasilnya dapat menyimpulkan identitas sebenarnya dari orang yang sedang diidentifikasi. Data gigi berupa rekam medik gigi (dental record) yang pernah dibuat saat masih hidup (antemortem) dan merupakan syarat utama yang harus ada saat melakukan identifikasi korban bencana menggunakan sarana gigi. [5]

Namun, sebelum mencapai tahap identifikasi, ada tahap paling utama yang harus dilakukan, yaitu tahap segmentasi. Segmentasi merupakan salah satu proses paling penting dalam pemrosesan citra. Untuk segmentasi gigi, yang dilakukan adalah dengan memisahkan masing-masing gigi agar nantinya dapat dilakukan pengekstraksian fitur lalu dapat dilanjutkan ke tahap klasifikasi dan yang terakhir ke tahap pencocokan citra (identifikasi) gigi dari data AM (antemortem) dengan data PM (postmortem).

Penelitian ini berfokus pada tahap segmentasi gigi. Didalam tahap segmentasi gigi yang dilakukan meliputi perbaikan kontras pada citra dan pemisahan untuk masing-masing gigi. Hasil dari segmentasi gigi ini nantinya dapat digunakan pada tahap klasifikasi gigi untuk penelitian di masa depan.

\section{METODE}

\section{Desain, Tempat, dan Waktu}

Penelitian dilakukan selama 9 (sembilan) bulan. Penelitian ini dilakukan di Rumah Sakit Pusat Angkatan Darat - Gatot Soebroto untuk pengambilan data berupa rekam medik gigi yang berjenis Dental Panoramic Radiograph dan Laboratorium Teknik Informatika Universitas $\mathrm{Al}$ Azhar Indonesia untuk pengolahan dan analisis data.

\section{Jenis dan Cara Pengumpulan Data}

Data yang digunakan dalam penelitian ini merupakan data berupa gambar berjenis Dental Panoramic Radiograph dengan format gambar berupa .JPG yang diperoleh dari Laboratorium Departemen Gigi dan Mulut RSPAD Gatot Soebroto. Dataset yang diberikan terdiri dari 343 gambar yang tidak terdapat informasi pasien didalamnya. Dataset tersebut dipilih secara acak dari berbagai jenis kelamin dengan kisaran waktu tahun 2017 dan 2018. Peneliti menggunakan data sebanyak 125 citra yang kemudian dilakukan cropping untuk mendapatkan citra yang lebih ke bagian giginya.

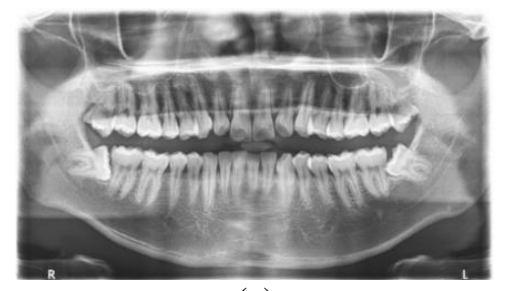

(a) 


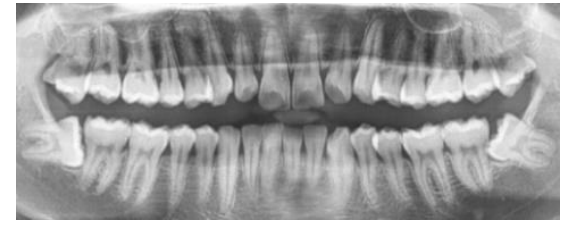

(b)

Gambar 1. Contoh citra sebelum (a) dan sesudah (b) dipotong

\section{Pengolahan Dan Analisis Data}

Berikut beberapa tahap dalam mengolah dan analisis data dental panoramic radiograh untuk segmentasi gigi:

\section{Data Rekam Medik Gigi}

Data yang digunakan dalam penelitian adalah Data Dental Panoramic Radiograph yang dimiliki oleh Rumah Sakit Pusat Angkatan Darat Gatot Soebroto. Data yang diberikan berjumlah 343 citra dengan dimensi yang bervariasi dan grayscale. Namun data yang digunakan peneliti sejumlah 125 citra.

\section{Preprocessing}

Peneliti perlu melakukan perubahan format gambar dari data yang dimiliki menjadi berformat .JPG agar dapat terbaca. Kemudian dilakukan pemotongan citra untuk mendapatkan citra yang sesuai dan hanya menampilkan bagian gigi saja.

\section{Image Enhancement}

Citra disamakan tingkat kecerahannya tergantung wilayahnya. Citra dibagi menjadi dua wilayah, yaitu wilayah foreground dan background. Bagian foreground adalah bagian gigi, sedangkan bagian background adalah bagian belakang gigi yang memiliki warna lebih gelap. Di tahap ini peneliti mencoba menggunakan metode Histogram Equalization.

\section{Upper-lower Jaw Separation}

Tahap ini dilakukan untuk menemukan jarak antara gigi pada rahang atas dan rahang bawah menggunakan Horizontal Integral Projection. Jarak yang dapat ditentukan adalah dilihat dari lembah terdalam saat melakukan gap valley detection. Lembah terdalah dapat dilihat dengan menentukan jumlah segmen (n-blok kolom).

\section{Tooth Segmentation}

Tahap terakhir ini dilakukan pemisahan masingmasing gigi baik gigi pada rahang atas maupun rahang bawah dengan menggunakan Vertical Integral Projection.

\section{Histogram Equalization}

Histogram Equalization merupakan salah satu teknik dalam melakukan image enhancement, dimana tingkat keabu-abuan terhadap gambar dilakukan pemetaan sehingga distribusi dari tingkat keabu-abuan dapat diratakan. Metode ini mengggunakan pemetaan monotonic non-linear yang dapat menetapkan kembali nilai intensitas piksel pada gambar yang dimasukkan dengan cara menghasilkan gambar keluaran yang intensitasnya telah diratakan secara seragam.

Dengan variabel $r$ melambangkan sebuah variabel acak yang menunjukkan tingkat keabuan pada suatu gambar. Diasumsikan bahwa $r$ bersifat kontinyu dan terletak pada interval tertutup [0:1] dengan $r=0$ yang mewakili warna hitam dan $r=1$ yang mewakili warna putih. Untuk setiap $r$ dalam interval tertentu, transformasinya seperti:

$$
S=T(r)
$$

Transformasi tersebut menghasilkan $s$ untuk setiap nilai piksel $T$ dalam gambar asli. Diasumsikan bahwa transformasi $T$ memenuhi kriteria:

- $\quad T(r)$ adalah fungsi bernilai tunggal, secara monoton akan meningkat dalam interval.

- $\quad T(r)$ terletak antara 0 dan 1.

Kondisi pertama mempertahankan urutan dari hitam menjadi putih di skala -keabu-abuan, dan kondisi kedua menjamin bahwa fungsi tersebut konsisten dengan rentang nilai piksel keabuan yang diperbolehkan. Kebalikan perubahan dari $s$ ke $r$ dapat direpresentasikan dengan

$$
r=T^{-1}(s)
$$

Dengan membiarkan tingkat keabuan yang asli dan yang telah berubah dicirikan dengan melihat masing-masing dari fungsi probabilitas densitas $p_{r}(r)$ dan $p_{s}(s)$. kemudiah dari teori awal probabilitas, jika $p_{r}(r)$ dan $p_{s}(s)$ diketahui dan jika $T^{-1}(s)$ memenuhi kondisi pertama, maka fungsi probabilitas densitas dari perubahan tingkat keabuan ditunjukkan dengan:

$$
P_{s}(s)=\left[P_{r}(r) \frac{d r}{d s}\right]_{r-T^{-1}(s)}
$$

Jika transformasinya diberikan dengan:

$$
s=T(r)=\int_{0}^{r} P_{r}(w) d w
$$

Kemudian mengganti $\frac{d r}{d s}=\frac{1}{p_{r}(r)}$ pada persamaan 3, maka diperoleh $P_{s}(s)=1$. Jadi memungkinkan untuk mendapatkan gambar dengan histogramnya telah diratakan menggunakan transformasi pada persamaan 4. [6] 
Jelas bahwa penggunaan fungsi transformasi sama dengan distribusi kumulatif dari $T$ (seperti yang diberikan pada persamaan 4) yang menghasilkan sebuah gambar yang tingkat keabuannya telah berhasil diseragamkan. Ini menjelaskan bahwa hasil transformasi dalam peningkatan rentang dinamis dari nilai piksel abu-abu yang dapat menghasilkan seperti apa yang ada di gambar ini.

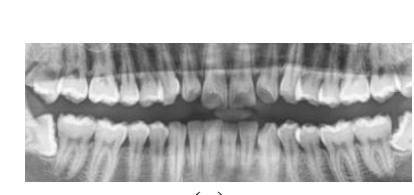

(a)

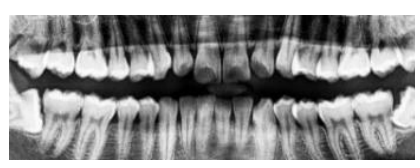

(c)

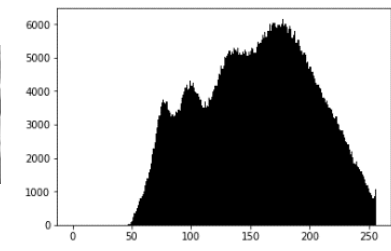

(b)

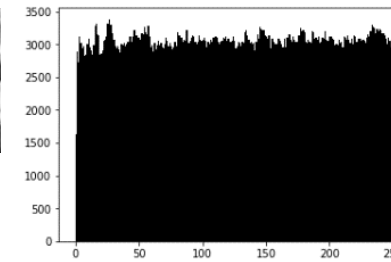

(d)

Gambar 2. Hasil Histogram Equalization

Pada Gambar 2. Terlihat bahwa bagian (a) adalah gambar asli, (b) merupakan histogram dari gambar asli, (c) adalah hasil dari histogram equalization danri gambar asli, dan (d) adalah hasil gambar dari proses histogram equalization.

\section{Image Segmentation}

Segmentasi citra adalah proses pemisahan citra secara digital menjadi beberapa segmen (kumpulan piksel atau biasa disebut super-piksel). Lebih tepatnya, segmentasi citra adalah proses pemberian label untuk setiap piksel pada gambar sehingga piksel dengan label yang sama memiliki karakteristik tertentu. Masing-masing piksel pada suatu wilayah (region) memiliki kesamaan karakteristik, seperti tingkat keabuan (grayscale), tekstur, intensitas, atau warna. Tujuan dari segmentasi adalah untuk menyederhanakan dan/atau mengubah representasi suatu gambar menjadi sesuatu yang lebih bermakna dan lebih mudah untuk dianalisis.

Terdapat tiga kategori dalam segmentasi citra, yaitu segmentasi berdasarkan threshold, segmentasi berdasarkan garis tepi (edge), dan segmentasi berdasarkan wilayah (region). Metode segmentasi berdasarkan wilayah (region) hanya memiliki dua operasi dasar, yaitu pemisahan (splitting) dan penggabungan (merging).
Metode dasar dari penggabungan (merging) dan pemisahan (splitting) dasar tampak menjadi pendekatan bottom-up dan top-down untuk metode segmentasi yang sama, tetapi ada perbedaan intrinsik: penggabungan dari dua segmen sangat mudah, tetapi pemisahan sebuah segmen mengharuskan untuk menetapkan sub-segmen yang sesuai yang bisa dibagi. Untuk menghindari masalah, pendekatan pemecahan (splitting) dasar sering ditingkatkan ke perpaduan pendekatan splitting dan merging, di mana segmen yang tidak homogen dibagi menjadi bentuk geometrik sederhana (biasanya menjadi empat kotak) secara rekursif. Ini tentu saja menciptakan batas-batas segmen (yang mungkin tidak berkorelasi dengan batas yang ada), dan langkah-langkah dari tahap merging dimasukkan ke dalam proses untuk menghapus batas-batas yang salah. [7]

\section{Upper-lower Jaws Separation}

Pemisahan rahang atas dan bawah ini dilakukan untuk memisahkan gigi menjadi gigi tunggal sehingga dapat digunakan fitur-fitur dari masingmasing gigi. Biasanya bagian gigi memiliki tingkat intensitas warna keabu-abuan lebih tinggi dibanding bagian rahang dan jaringan lainnya. Celah antara gigi atas dan gigi bawah itulah yang akan membentuk 'lembah' pada sumbu y untuk proyeksi histogram, yang dapat disebut dengan gap valley. Namun, nantinya akan banyak muncul 'lembah' pada proyeksi.

Cara menemukan gap valley adalah dengan melihat 'lembah' terdalam pada proyeksi tersebut. Biasanya hanya satu 'lembah' terdalam yang muncul pada proyeksi. Lembah itulah yang dapat dijadikan titik untuk gap valley dalam membuat horizontal integral projection.

$$
H(y)=\sum_{x=1}^{m} I(x, y)
$$

Dengan $I(x, y)$ merupakan citra dengan dimensi $m \times$ $n$. Penjumlahan dilakukan terhadap nilai level keabuan setiap piksel pada baris $\mathrm{x}$ dan kolom $\mathrm{y}$. Horizontal integral projection bekerja dengan menjumlahkan nilai-nilai piksel secara horizontal dari setiap kolom. Horizontal (sumbu-y) integral projection ini akan membantu dalam membuat garis pemisah antara rahang atas dan rahang bawah. Biasanya, diantara rahang atas dan rahang bawah terdapat celah ( $g a p)$, maka histogram proyeksi pada sumbu y akan membentuk lembah (valley). Jadi, garis pemisah pada posisi dengan nilai terkecil dari histogram proyeksi pada sumbu y dapat dianggap sebagai garis terbaik untuk memisahkan kedua rahang. 


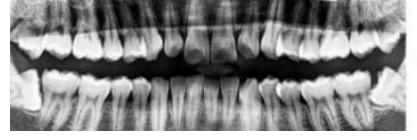

Gambar 3. Penerapan Horizontal Integral Projection dengan menentukan n-blok kolom

Lembah terdalam tersebut dipilih berdasarkan nilai piksel paling minimum. Selanjutnya, dilakukan pemisahan menjadi beberapa bagian dengan menentukan n-blok kolom. Nilai dari n-blok kolom (dengan nilai n-blok kolom minimal adalah 2) ini dijumlah berdasarkan nilai paling minimum yang diharapkan berada di sela antar rahang. Nilai piksel dari n-blok kolom yang telah ditentukan akan menjadi garis inisial untuk menjadi garis pemotong rahang. Pemecahan citra dilakukan di sepanjang garis inisial yang disebut dengan stripe. Kemudian, proses dari beberapa titik pemotong antar rahang dihubungkan dengan pembuatan garis pembatas menggunakan metode spline. Contohnya seperti pada Gambar 3. yang melakukan penerapan horizontal integral projection dengan jumlah n-blok kolom sebanyak 6 blok kolom.

\section{Cubic Spline Interpolation}

Metode Spline adalah salah satu metode numerik yang dapat digunakan untuk melakukan pencarian interpolasi. Interpolasi berguna untuk menaksir nilai tengah antara titik data yang ditemukan. Interpolasi mempunyai orde atau derajat. Interpolasi spline kubik menurunkan polinom orde ketiga untuk setiap selang di antara simpul, seperti:

$$
f(x)=a_{i} x^{3}+b_{i} x^{2}+c_{i} x+d_{i}
$$

Untuk $\mathrm{n}+1$ titik data $(i=0,1,2, \ldots, n)$, terdapat $n$ interval, maka diperlukan $4 n$ konstanta yang harus dicari. Spline kubik memiliki peran penting dalam pemodelan, misalnya animasi dan skala gambar. Pada pengolahan gambar, spline terbukti berguna dalam pembesaran gambar berkualitas tinggi. [8]

Cubic Spline interpolation digunakan untuk menghubungkan titik-titik data yang berdekatan dengan menggunakan garis. Titik data ini didapat dari hasil nilai n-blok kolom yang telah ditentukan saat pencarian gap valley. Hasil dari cubic spline interpolation menandakan bahwa tahap Horizontal Integral Projection telah berhasil dilakukan dengan membentuk garis pemisah antara gigi atas dan gigi bawah. Contohnya seperti pada Gambar 5. yang melakukan Spline Interpolation menggunakan nilai dari hasil Horizontal Integral Projection dengan nblok kolom sebanyak 6 .

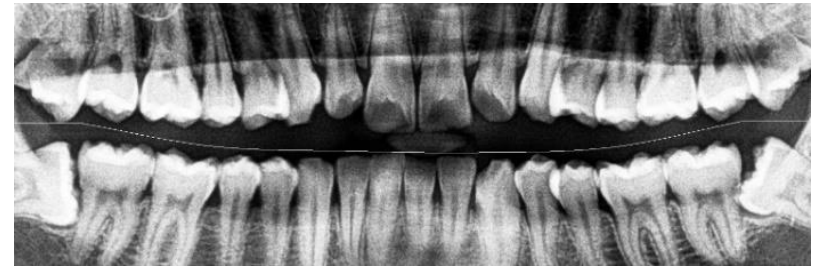

Gambar 4. Penerapan Cubic Spline Interpolation dari hasil Horizontal Integral Projection

\section{Tooth Segmentation}

Tahap ini adalah salah satu tahap untuk melakukan Vertical Integral Projection. Sebelum melakukan Average Filter dibutuhkan mencari gap valley pada posisi vertikal. Berbeda dengan saat mencari gap valley untuk horizontal projection yang cukup menemukan satu lembah terdalamnya, vertical integral projection ini mencari semua gap valley yang terbentuk dari celah diantara masing-masing gigi di sekitarnya, baik itu gigi atas maupun gigi bawah.

$$
V(x)=\sum_{y=1}^{n} I(x, y)
$$

Dengan $I(x, y)$ merupakan citra dengan dimensi $m \times$ $n$. Penjumlahan dilakukan terhadap nilai level keabuan setiap piksel pada baris $\mathrm{x}$ dan kolom $\mathrm{y}$. Vertical integral projection bekerja dengan menjumlahkan nilai-nilai piksel secara vertikal dari setiap baris.

Di dalamnya terdapat slopes yang berada di antara dua gigi. Slopes inilah yang bisa menemukan jarak pemisah antara gigi dengan perubahan nilai dari negatif ke positif. Namun, nilai dari slopes dapat berubah-ubah sehingga memungkinkan untuk terjadinya over-segmentation, karena dapat mendeteksi posisi-posisi dengan variasi kecil. Oleh sebab itu, butuh average filter untuk menghilangkan variasi kecil yang ada pada vertical projection menggunakan rumus:

$$
V(x)=\frac{V(x-2)+V(x-1)+V(x)+V(x+1)+V(x+2)}{\text { size }}
$$

Dengan: $V(x)$ adalah vertical projection, dan size adalah parameter untuk melakukan average filtering. Nilai dari size yang dapat digunakan adalah angka ganjil.

Strip windowing juga dibutuhkan dalam vertical integral projection untuk membentuk ukuran dari masing-masing gigi agar mendapatkan gap valley yang benar-benar sesuai dengan ukuran gigi. Terbentuknya strip windowing dapat disempurnakan dengan menentukan nilai average filter agar mendapatkan ukuran yang sesuai dengan gigi yang terdapat di dalam citra. Strip window dibentuk 
dengan ukuran $(40,20)$ yang diatur di sekitar garis pemisah vertikal. Setiap pergeseran dari strip window dilakukan penjumlahan, titik yang paling minimum akan dipilih sebagai titik pemisah antar gigi. Selanjutnya beberapa koordinya titik yang ditemukan dari strip windowing itulah yang nantinya dihubungkan dengan membuat garis pemisah seperti pada saat horizontal integral projection, yaitu menggunakan cubic spline interpolation.
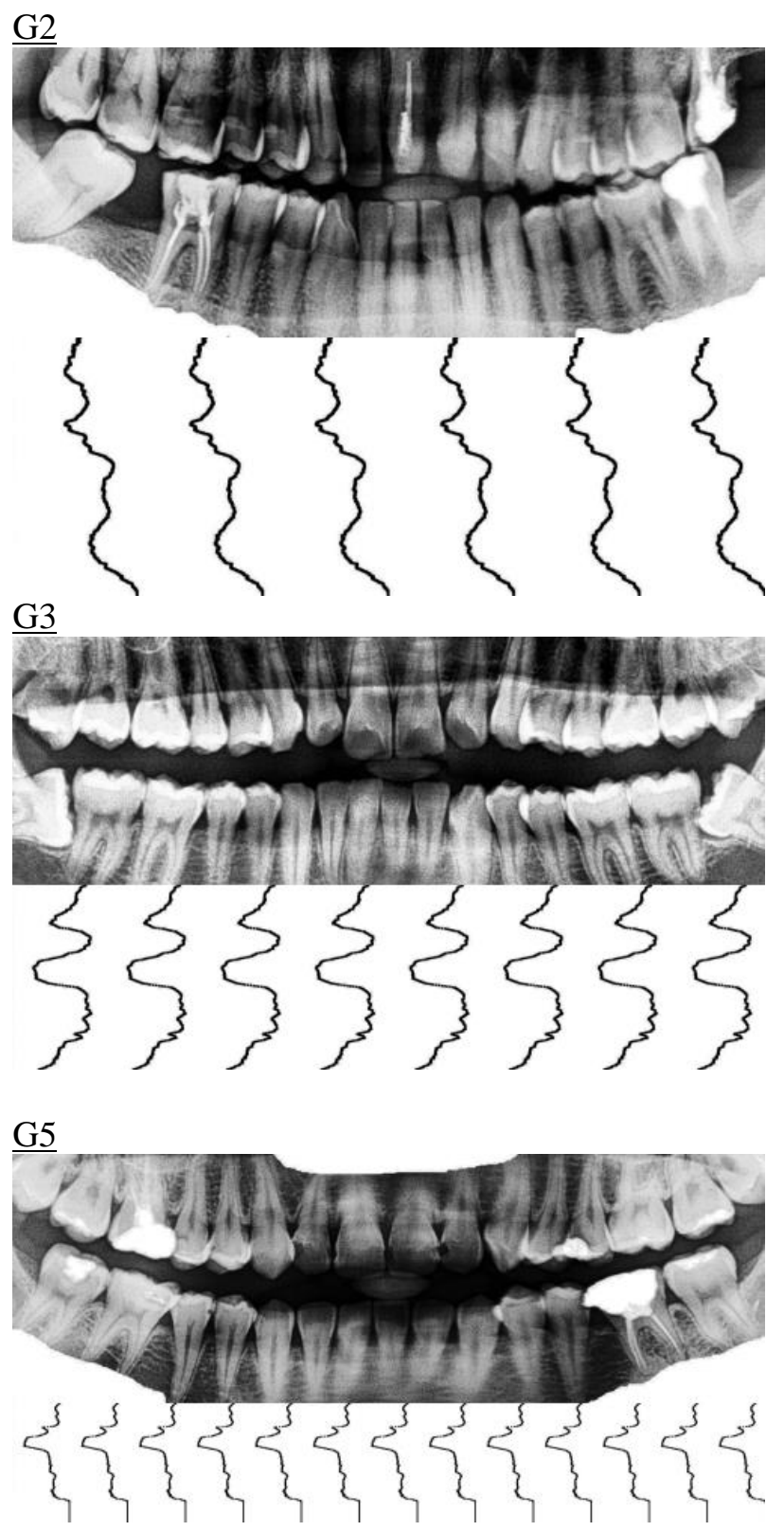

Gambar 5. Citra hasil penerapan cubic spline interpolation

\section{HASIL DAN PEMBAHASAN}

Citra yang digunakan untuk penelitian sebanyak 125 data yang berjenis dental panoramic radiograph. Tabel 1 merupakan beberapa citra yang dilakukan perbaikan intensitas warna dan pencahayaan terhadap citra.

Tabel 1. Perbandingan citra asli dengan citra hasil Histogram Equalization

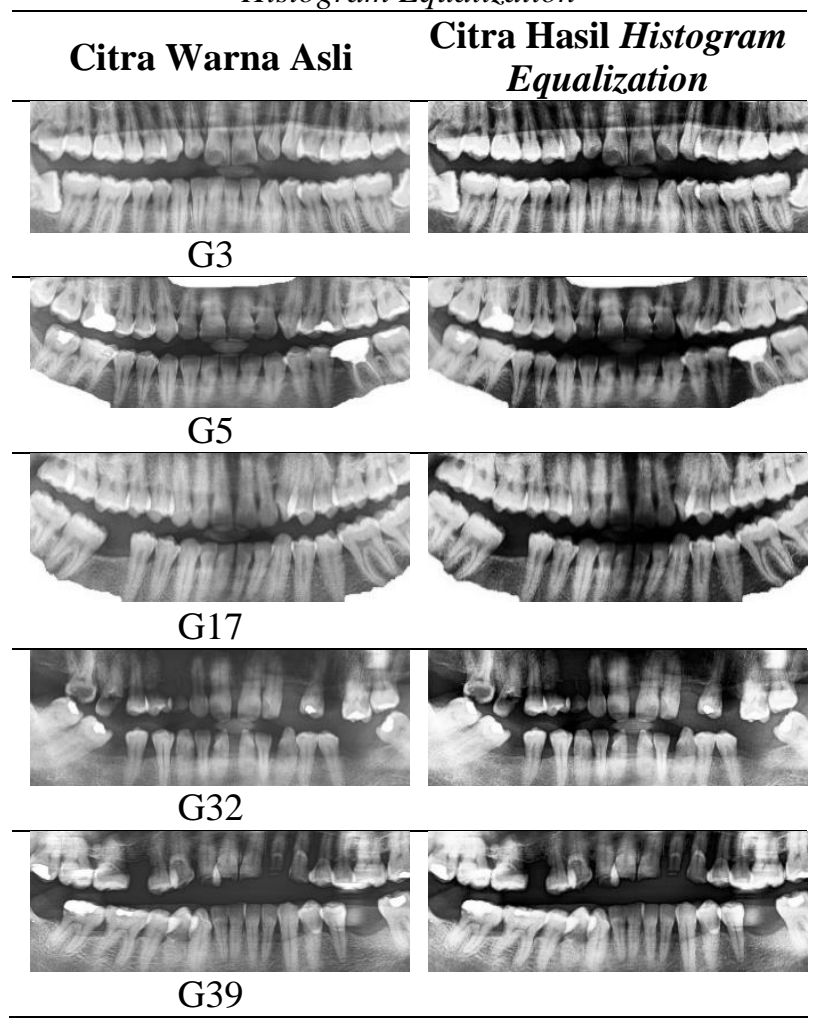

Hasil dari proses image enhancement yang diharapkan adalah meningkatkan tingkat kecerahan terhadap bagian foreground pada citra dan meningkatkan tingkat kecerahan terhadap bagian background (bagian belakang gigi tetap menjadi lebih hitam).

Uji Coba Pemisahan Rahang Atas-Bawah dengan Horizontal Integral Projection

Citra hasil dari proses Image Enhancement dilakukan untuk memberi garis pemisah antara rahang atas dan rahang bawah, atau gigi atas dan gigi bawah. Di dalamnya terdapat dua proses yang perlu dilakukan, yaitu proses untuk Horizontal Integral Projection dan menggambar garis pemisah menggunakan proses Cubic Spline Interpolation. 
Dari Gambar 5 terlihat bahwa tiga citra yang sama menggunakan nilai n-blok kolom yang beragam, dengan (G2) nilai n-blok kolom adalah 13, (G3) nilai n-blok kolom adalah 6, dan (G5) nilai n-blok kolom adalah 8. Penentuan nilai n-blok kolom ini berdasarkan pada bentuk gap valley yang muncul. Terbentuknya lembah terdalam ini mengikuti nilai pixel dari citra yang berwarna gelap (mendekati 0 ). Jika lembah terdalam berada di posisi diantara gigi atas dan gigi bawah maka nantinya garis yang terbentuk dapat menghasilkan garis horizontal yang benar-benar dapat memisahkan bagian rahang atas dan bawah. Pembentukan garis horizontal ini membutuhkan metode Cubic Spline Interpolation.

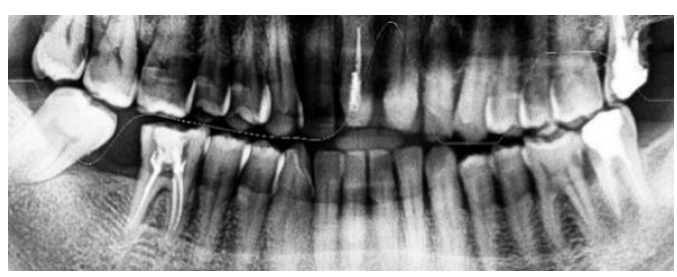

G2

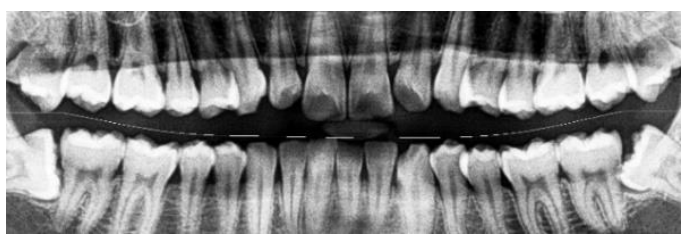

$\underline{\mathrm{G} 3}$

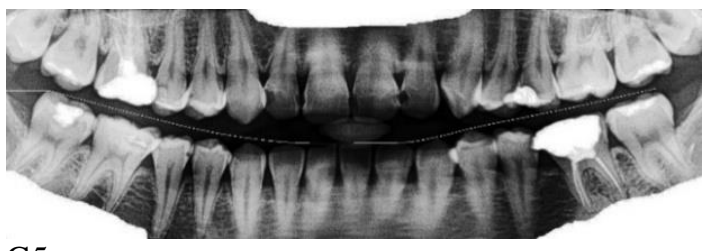

G5

Gambar 6. Penerapan Horizontal Integral Projection terhadap citra hasil dari Image Enhancement

Dari citra yang dihasilkan seperti pada Gambar 6 . dengan (G2) n-blok kolom = 13, (G3) n-blok kolom $=6$, (G5) n-blok kolom $=8$, terlihat bahwa $(\mathrm{G} 2)$ tidak membentuk garis pemisah horizontal secara sempurna. Ini karena ketika Spline Interpolator sedang membuat garis menggunakan nilai dari hasil horizontal integral projection, ditemukan warna yang lebih gelap dibanding warna yang sudah ditandai saat pencarian lembah (warna yang berada diantara gigi atas dan gigi bawah) sehingga terbentuklah garis yang menurun (karena mengikuti warna yang lebih gelap) tersebut.

Pada citra yang lain, cara penentuan nilai n-blok kolom agar mendapatkan posisi di antara rahang atas dan bawah dapat diilustrasikan seperti pada Gambar 7.

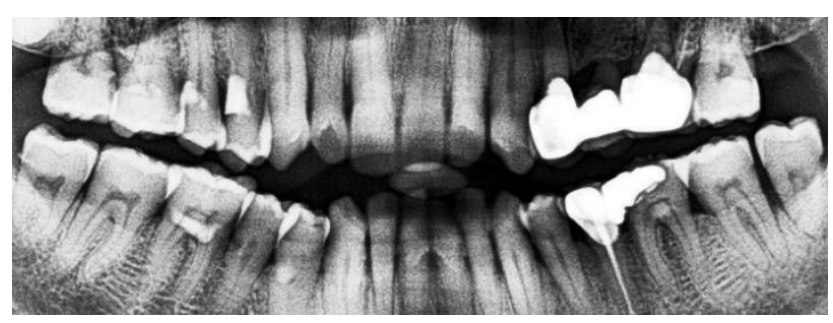

$\underline{\mathrm{G} 13}$

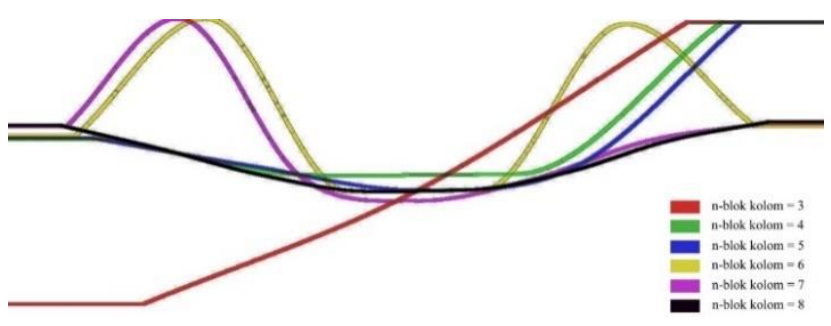

(a)

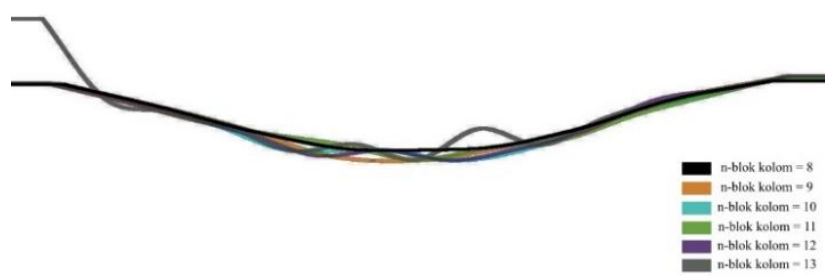

(b)

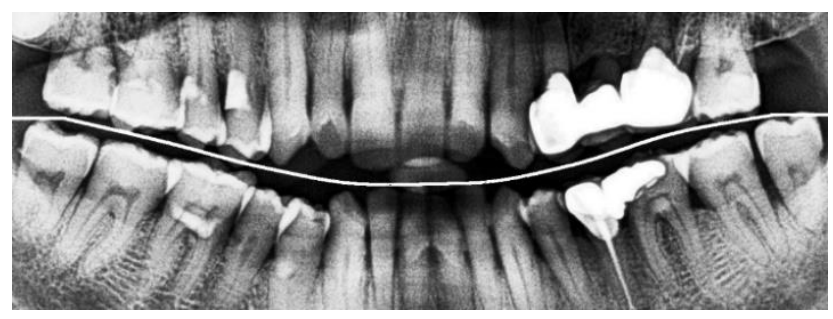

(c)

Gambar 7. Penyesuaian nilai n-blok kolom untuk pemisahan rahang atas dan rahang bawah

Di Gambar 7 terlihat bahwa perlu dilakukan beberapa pengecekan dalam menentukan nilai nblok kolom. Untuk citra G13, peneliti mencoba menentukan parameter dalam percobaan nilai n-blok kolom dari 3 hingga 13. Pada Gambar 7. (a) merupakan percobaan pencarian nilai n-blok kolom yang sesuai untuk memotong daerah antara gigi atas dan bawah dengan parameter 3 hingga 8 . Pada saat n-blok kolom bernilai 8 , garis yang dihasilkan sudah berada di antara gigi atas dan gigi bawah. Kemudian pada Gambar 7. (b) terlihat bahwa n-blok kolom dengan nilai 8 hingga 12 menghasilkan garis yang hamper sama, namun saat dicoba hingga n-blok kolom $=13$, garis yang dihasilkan mulai berubah 
jauh. Sehingga nilai n-blok kolom yang digunakan pada Gambar 7. (c) adalah sebesar 8.

\section{Uji Coba Pemisahan Gigi Tunggal dengan Vertical Integral Projection}

Setelah melakukan pemisahan antara gigi atas dan gigi bawah menggunakan horizontal integral projection, selanjutnya mencari gap valley untuk masing-masing gigi menggunakan nilai slope yang muncul pada celah (gap) antara masing-masing gigi. Setelah menemukan nilai slope diterapkan Average Filter untuk memperbaiki posisi pada celah (gap) untuk menghindari terjadinya over-segmented. Kemudian divisualisasikan dengan membuat Strip Window untuk melihat posisi mana saja terbentuknya garis pemisah vertikal. Lalu dibentuk garis pemisah vertikal dengan spline interpolation.

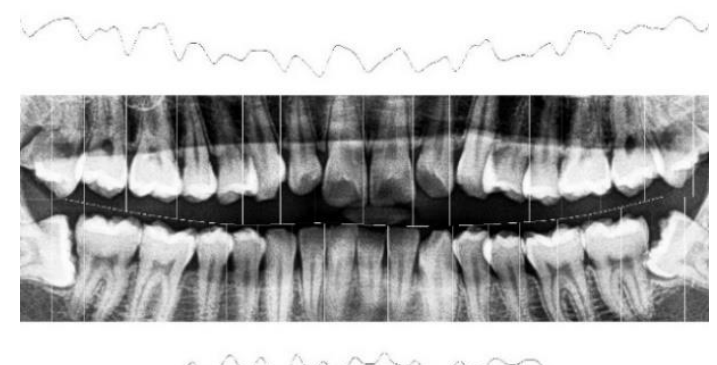

(a)

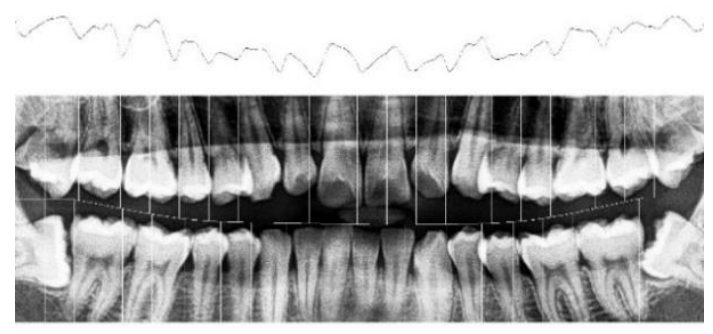

(b)

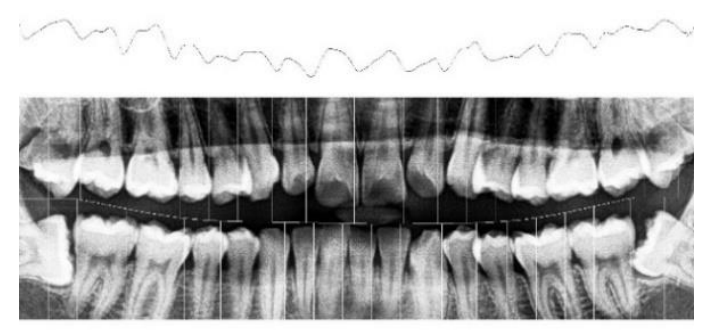

(c)

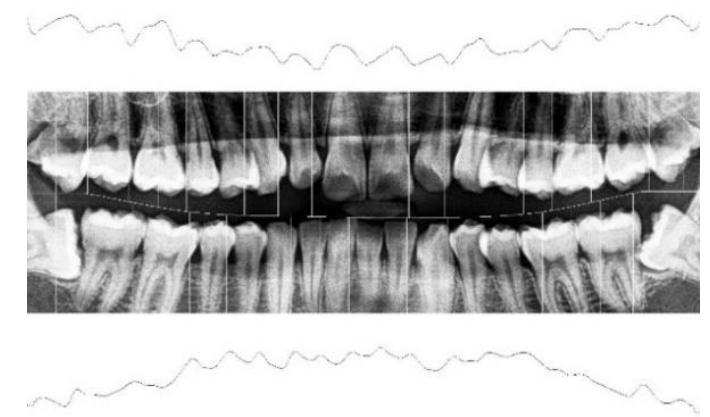

(d)

Gambar 8. Hasil Strip Windowing dengan penentuan nilai Average Filter untuk Vertical Integral Projection

Pada Gambar 8. dengan satu citra yang sama tetapi nilai untuk average filter yang berbeda, seperti (a) menggunakan average filter sebesar 17, (b) menggunakan average filter sebesar 23, (c) menggunakan average filter sebesar 33, dan (d) menggunakan average filter sebesar 43. Terlihat bahwa setiap nilai average filter yang ditentukan dapat mempengaruhi pembuatan garis pemisah vertikal untuk masing-masing gigi. Setiap masingmasing citra memiliki nilai average filter yang berbeda sehingga peneliti tidak bisa menyamaratakan nilainya demi mendapatkan model yang sesuai untuk melakukan pemisahan gigi. Pada Gambar 9 merupakan citra dengan nilai average filter adalah 17.

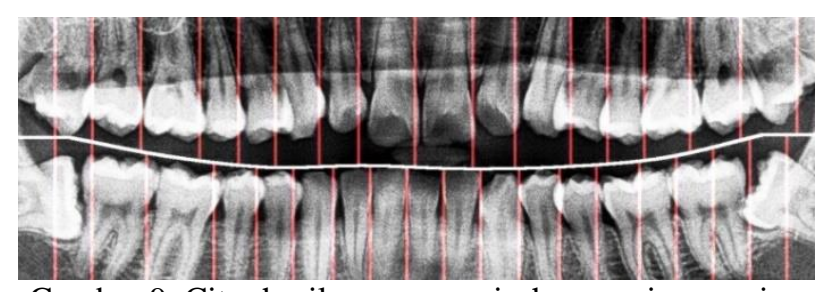

Gambar 9. Citra hasil proses pemisahan masing-masing gigi

Untuk perbandingan, citra dilakukan horizontal integral projection dan vertical integral projection.

Tabel 2. Hasil Horizontal Integral Projection dan vertical integral projection

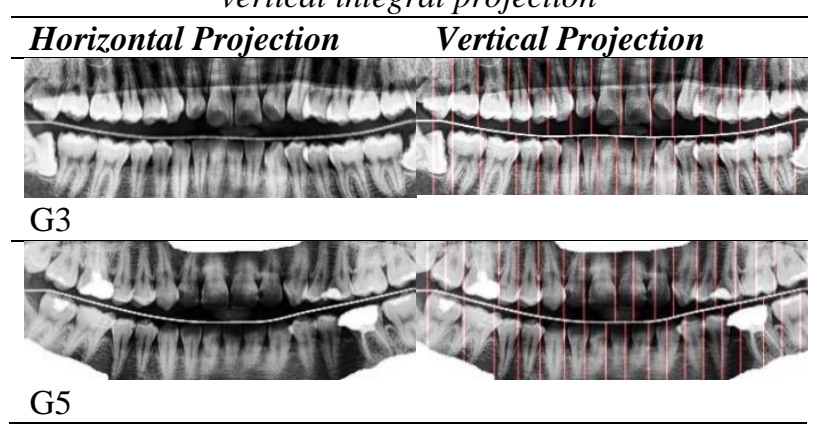




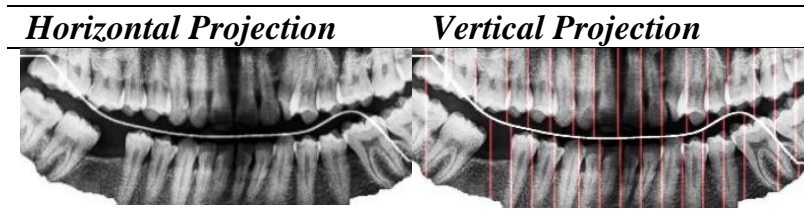

G17

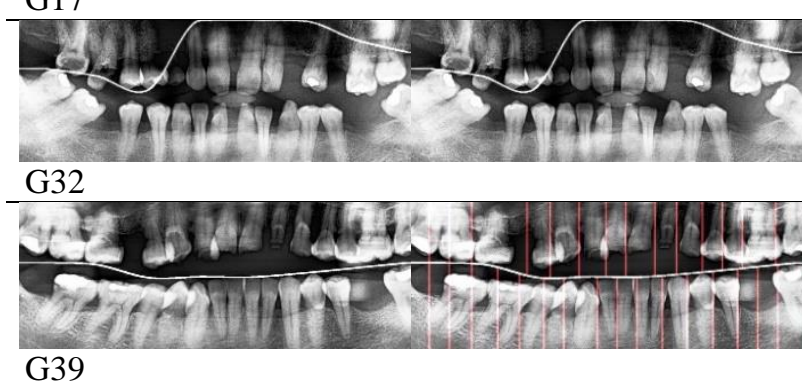

Tabel 2 merupakan penerapan horizontal integral projection dan vertical integral projection pada citra yang sama. Pada saat melakukan horizontal integral projection, kelima citra menggunakan nilai n-blok kolom $=8$. Pada tabel 2 terlihat bahwa (G17) dan (G32) dapat disebut sebagai citra yang mengalami kegagalan saat melakukan pemisahan rahang atas dan rahang bawah terhadap citra. Karena garis yang terbentuk tidak berada tepat di warna gelap antara gigi atas dan bawah. Melainkan membentuk garis pada daerah gelap pada bagian gusi. Jika garis horizontal integral projection yang dihasilkan tidak sesuai dengan yang diharapkan, maka akan berpengaruh ketika melakukan pemisahan gigi tunggal sehingga pemisahannya tidak maksimal. Sebenarnya untuk citra (G17), saat melakukan horizontal integral projection, citra tersebut dapat membentuk garis pemisah antara rahang atas dan bawah dengan cukup baik, hanya saja nilai $\mathrm{n}$-blok kolom yang digunakan adalah 23 seperti pada Gambar 10.

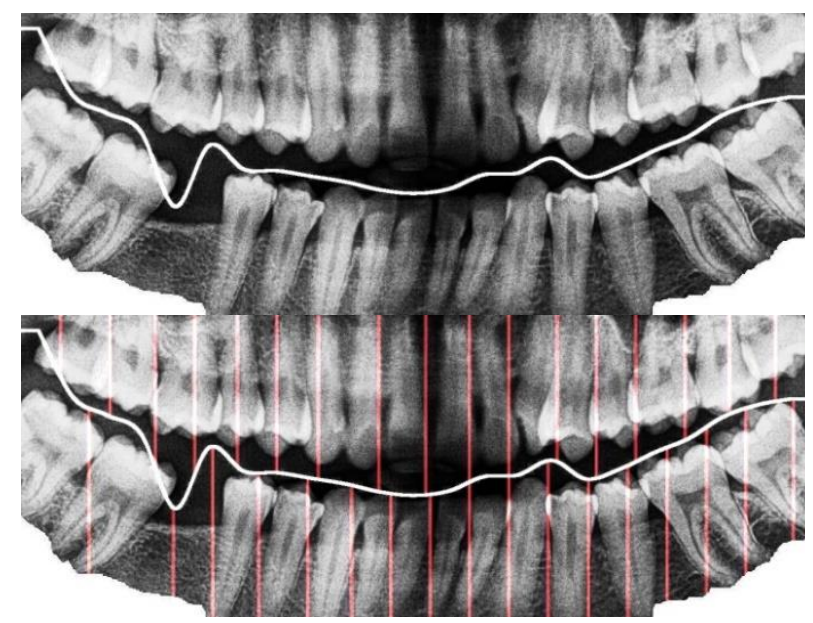

Gambar 10. Perbaikan n-blok kolom pada citra (G17)

Pada Gambar 10 terlihat bahwa ketika nilai n-blok kolom yang digunakan adalah 23, garis yang terbentuk dari horizontal integral projection berada di daerah gelap antara gigi atas dan gigi bawah sehingga dapat mempengaruhi pada saat melakukan pemisahan gigi tunggal dengan vertical integral projection.

\section{Hasil Uji Keseluruhan}

Hasil pengujian model secara keseluruhan terhadap 125 data citra yang dimiliki kemudian dilakukan pengecekan akurasi dari segmentasi yang telah dijalankan. Akurasi keberhasilan dan kegagalan untuk pemisahan gigi diukur secara manual dengan hasil kebenarannya dilihat secara visual oleh peneliti.

Angka akurasi diperoleh dengan rumus sebagai berikut:

$$
\begin{gathered}
\text { Error rate } \mathrm{HIP}=\frac{g}{n} \times 100 \% \\
\text { MAE (Mean Absolute Error })=\frac{1}{n} \sum_{i=1}^{n}\left|y_{i}-\hat{y}_{i}\right|
\end{gathered}
$$

Dengan :

$g:$ total citra yang gagal dipisahkan

$y_{i}$ : jumlah gigi keseluruhan untuk satu citra

$\hat{y}_{i}$ : estimasi jumlah gigi yang berhasil disegmentasi $\mathrm{n}$ : total citra keseluruhan

Gigi yang berhasil dipisahkan ini maksudnya adalah setiap gigi yang ROI (Region of Interest) -nya tersegmentasi mengandung gigi tunggal dimana gigi ada atau tidak ada gigi dimana gigi yang hilang dapat terdeteksi. Gigi yang tidak berhasil disegmentasi dilihat dari citra pada masing-masing gigi yang mengalami over segmentation dan under segmentation.

Tabel 3. Hasil error rate pada saat horizontal integral projection

\begin{tabular}{cc}
\hline N-Blok Kolom & $\begin{array}{c}\text { Error rate Horizontal } \\
\text { Integral Projection }\end{array}$ \\
\hline 3 & $70.4 \%$ \\
\hline 8 & $56.8 \%$ \\
\hline 13 & $62.4 \%$ \\
\hline 18 & $67.2 \%$ \\
\hline 23 & $68 \%$ \\
\hline 28 & $72.8 \%$ \\
\hline
\end{tabular}

Tabel 3. merupakan hasil keseluruhan citra gigi yang mengalami error saat dilakukan pemisahan rahang atas dan rahang bawah. Perhitungan evaluasi ini menggunakan cara manual, pencarian error pada citra dengan cara memperhatikan masing-masing citra secara visual menggunakan pengelihatan manusia.

Dari 125 citra, terdapat 48 citra yang gagal pada tahap horizontal integral projection dengan nilai nblok kolom yang telah ditentukan sehingga mempengaruhi kegagalan lainnya dalam melakukan 
pemisahan masing-masing gigi menggunakan nilai average filter yang ditentukan. Pada tabel, terlihat bahwa n-blok kolom yang bernilai 8 yang memiliki hasil optimum dalam penerapan horizontal integral projection. Sehingga peneliti menggunakan nilai nblok kolom $=8$ untuk tahap selanjutnya, yaitu vertical integral projection seperti pada Tabel 4.

\begin{tabular}{|c|c|c|}
\hline $\begin{array}{c}\text { Average } \\
\text { Filter }\end{array}$ & $\begin{array}{c}\text { MAE } \\
\text { (per citra) }\end{array}$ & $\begin{array}{c}\text { Error rate } \\
\text { (per gigi) }\end{array}$ \\
\hline 5 & 12.44 & $41.65 \%$ \\
\hline 9 & 12.24 & $40.95 \%$ \\
\hline 13 & 11.52 & $38.59 \%$ \\
\hline 17 & 11.42 & $38.27 \%$ \\
\hline 21 & 11.72 & $39.19 \%$ \\
\hline 25 & 12.98 & $43.31 \%$ \\
\hline
\end{tabular}

Tabel 4. menggunakan n-blok kolom dengan nilai 8 dan hasil error rate yang muncul pada saat menggunakan nilai average filter yang telah ditentukan. Dari 125 citra, total citra yang digunakan untuk n-blok kolom $=8$ adalah 54 dengan jumlah gigi keseluruhan adalah 1609. Pada tabel terlihat bahwa nilai kesalahan terkecil yang terjadi pada saat melakukan segmentasi untuk masing-masing gigi adalah dengan menggunakan nilai average filter sebesar 17.

Jika dilihat dari hasil segmentasi gigi pada Tabel 4., berikut ini ada beberapa faktor yang menyebabkan terjadinya kegagalan dalam proses segmentasi:

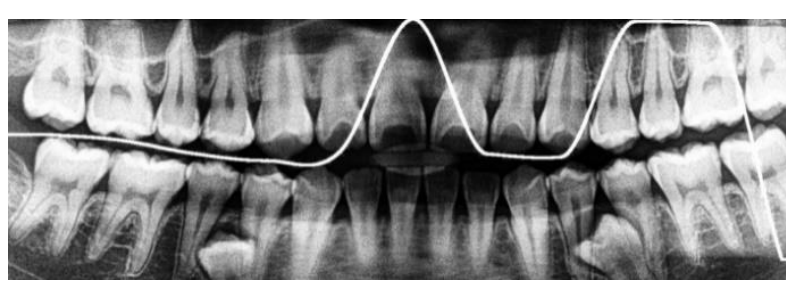

G119

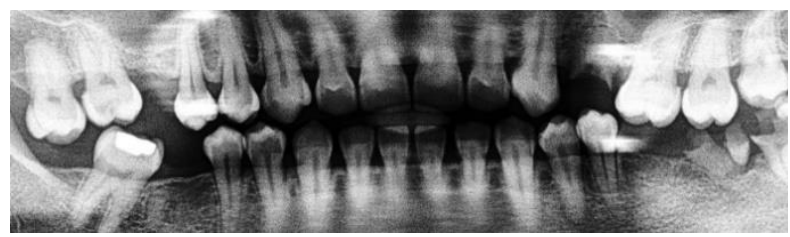

G116

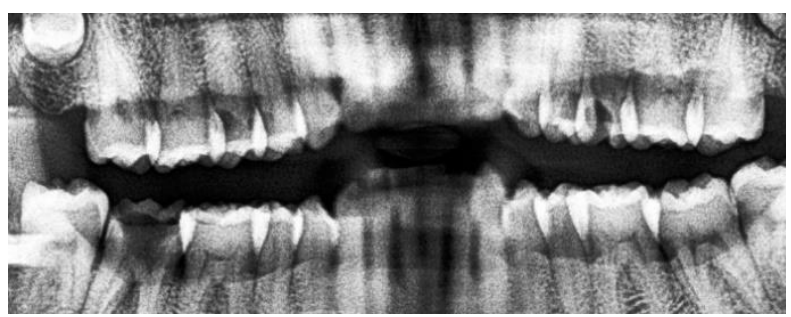

G31

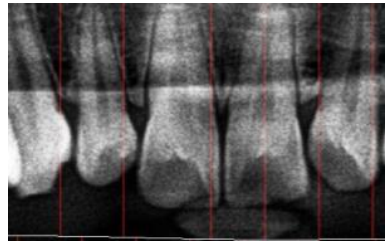

G3

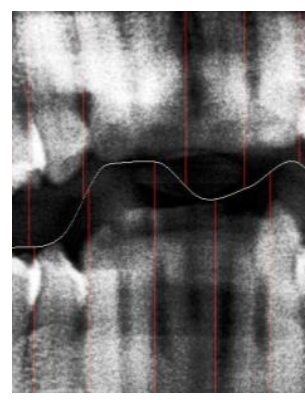

G31

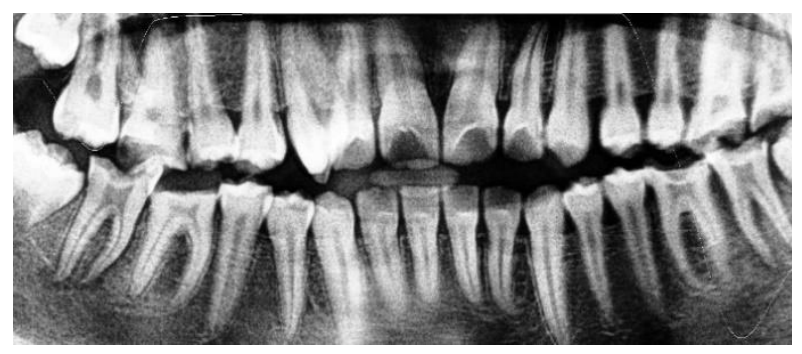

G123

Gambar 11. Penyebab Kegagalan Segmentasi Gigi

Pada Gambar 11. terlihat beberapa penyebab terjadinya kegagalan dalam melakukan segmentasi gigi, diantaranya adalah:

Pada G119 terlihat bahwa garis horizontal integral projection tidak terbentuk sempurna karena terlalu banyak daerah pada citra yang berwarna gelap.

Pada G116 terlihat bahwa jarak antara gigi atas dan gigi bawah terlalu sempit dan banyak daerah yang tingkat warna gelapnya tinggi sehingga garis horizontal integral projection tidak terbentuk di antara gigi atas dan bawah dengan sempurna.

Pada G3 terjadi oversegmentation pada gigi yang membuat gigi tersebut tidak dapat dihitung untuk yang berhasil disegmentasi.

Pada G31 terdapat bagian gigi di dalam citra yang buram sehingga terjadi undersegmentation pada gigi yang membuat dua gigi tersebut tidak terhitung sebagai yang berhasil disegmentasi.

Pada G123 merupakan salah satu citra yang gagal saat dilakukan segmentasi karena hampir semua garis horizontal integral projection terbentuk bukan di antara celah gigi atas dan bawah melainkan di area yang terdapat banyak piksel bernilai 0 , untuk citra ini berada di bagian gusi pada rahang atas.

\section{KESIMPULAN}

Dari 125 citra yang digunakan, terdapat 48 citra yang gagal pada tahap horizontal integral projection 
dengan nilai n-blok kolom yang telah ditentukan. Hasil evaluasi menunjukkan bahwa error rate terkecil ditemukan saat melakukan pemisahan rahang atas dan rahang bawah menggunakan horizontal integral projection dengan penentuan nblok kolom sebesar 8 adalah $56.8 \%$. Untuk hasil evaluasi error rate terkecil yang ditemukan saat segmentasi gigi pada tahap vertical integral projection sebesar $38.27 \%$ dengan nilai average filter sebesar 17.

Beberapa faktor yang menyebabkan citra gigi gagal disegmentasi, yaitu (i) terlalu banyak gigi dengan arah yang tidak normal sehingga saat dilakukan segmentasi menggunakan metode Integral Projection, pemetaannya tidak tepat saat dilakukan pemisahan gigi; (ii) pembentukan garis horizontal integral projection menjadi tidak sesuai ketika intensitas warna gelap pada citra terlalu banyak; (iii) pada saat pembentukan garis vertical integral projection terjadi kelebihan saat memisahkan gigi untuk tiap wilayah (over segmentation) dan ada beberapa bagian gigi yang tidak dipisahkan (under segmentation) sehingga tidak berhasil terhitung sebagai gigi yang tersegmentasi.

Beberapa hasil dilakukannya segmentasi gigi masih terdapat banyak terjadinya over-segmentation dan under-segmentation. Untuk penelitian selanjutnya diharapkan dapat mengatasi masalah tersebut agar mendapatkan garis yang lebih presisi terhadap masing-masing gigi dan dapat menempatkan garis di posisi gigi yang berlubang.

Model yang telah dihasilkan pada penelitian ini mencapai segmentasi gigi. Untuk penelitian selanjutnya (klasifikasi dan identifikasi) yang dapat dilakukan meliputi: ekstraksi fitur (segmentasi secara mendalam dengan memperhatikan garis tepi gigi, teksur, ukuran, dan lain-lain), yang selanjutnya dilakukan pencocokan bentuk gigi dan mencari ukuran yang sesuai untuk nantinya dapat digunakan saat mencocokkan citra antemortem dengan citra postmortem.

\section{UCAPAN TERIMA KASIH}

Kepada Rumah Sakit Pusat Angkatan Darat Gatot Soebroto bagian Poliklinik Gigi dan Mulut yang telah memberikan ijin untuk menggunakan data Dental Panoramic Radiograph kepada peneliti.

Kepada UPN Veteran Jakarta Fakultas Kedokteran bagian Pengurus Etik yang telah memberi ijin persetujuan etik (ethical clearance) kepada peneliti untuk melakukan penelitian data yang berkaitan dengan milik pasien rumah sakit.

\section{DAFTAR PUSTAKA}

[1] Trisnowahyuni, H. R. Agus, I. D. Eddie, "Rekam Medis Odontogram Sebagai Alat Identifikasi Dan Kepentingan Pembuktian di Pengadilan," SOEPRA Jurnal Hukum Kesehatan, pp. 117-131, 2017.

[2] UNAIR, "Peran Dokter Gigi dalam Identifikasi Korban Bencana," UNAIR, 17 Oktober 2008. [Online]. http://www.unair.ac.id/peran-dokter-gigidalam-identifikasi-korban-bencana-berita 963.html. [Diakses: 6 April 2018]

[3] N. Purnamasari, "Data Terkini Korban dan Kerusakan Gempa-Tsunami Palu," Detik.com, 29 September 2018. [Online]. https:// news.detik.com /berita/4234343/data-terkini-korban-dan-kerusakangempa-tsunami-palu. [Diakses: 3 Desember 2018]

[4] D. R. M. Novia, "Cara Identifikasi Korban Kecelakaan Pesawat Terbang," JawaPos.com, 5 November 2018. [Online]. https://www.jawapos.com/dw/05/11/2018/caraidentifikasi-korban-kecelakaan-pesawat-terbang. [Diakses: 3 Desember 2018].

[5] A. Sara, "Peran Odontologi Forensik Sebagai Salah Satu Sarana Pemeriksaan Identifikasi Jenazah Tak Dikenal," Bagian Ilmu Kedokteran Forensik Fakultas Kedokteran Universitas Gajah Mada, Yogyakarta, 1999.

[6] T. Acharya dan A. K. Ray, Image Processing: Principle and Application, Hoboken, New Jersey: JOHN WILEY \& SONS, Inc., Publication, 2005.

[7] Departement of Information and Computing Sciences, "Chapter 10 Segmentation," Departement of Information and Computing Science, Utrecht University, pp. 310-311.

[8] E. Kaya, "Spline Interpolation Techniques," Journal of Technical Science and Technologies, pp. 47-52, 2014. 